\title{
Variation of physical properties of LDPE greenhouse films due to agrochemicals used during cultivation
}

\author{
Evelia Schettini*, Giuliano Vox \\ Department of Agricultural and Environmental Science, University of Bari, Italy
}

\begin{abstract}
During protected cultivation, the use of agrochemicals influence the degradation of the greenhouse plastic films. A research was carried out to evaluate how agrochemicals contamination and solar radiation influence the physical properties of low density polyethylene (LDPE) films. The LDPE films were manufactured on purpose adding different anti-UV stabilizer systems and were exposed to natural outdoor weathering at the experimental farm of the University of Bari (Italy; $41^{\circ} 05^{\prime}$ $\mathrm{N})$. Each film was tested as covering of two low tunnels: one was sprayed from inside with commercial agrochemicals containing iron, chlorine and sulphur while the other one was not sprayed and used as control. Radiometric tests were carried out on the new films and on film samples taken at the end of the trial. Analyses on absorption of the selected contaminants were carried out in laboratory on the samples taken at the end of the exposure in the field in order to compare the relative effectiveness of the stabilizing systems under evaluation. The experimental tests showed that the natural weathering together with the agrochemicals did not modify significantly the radiometric properties of the films in the solar and PAR wavelength range. Significant variations were recorded for the stabilised films in the LWIR wavelength range.
\end{abstract}

Correspondence: Evelia Schettini, Department of Agricultural and Environmental Science, University of Bari, via Amendola 165/A - 70126 Bari, Italy.

Tel. +39080 5443060- Fax+390805442977.

E-mail: evelia.schettini@uniba.it

Key words: chlorine, HALS, iron, radiometric properties, solar radiation, sulphur.

Acknowledgements: the present work has been carried out under the projects funded by P.A.T.I. S.p.A. (San Zenone degli Ezzelini, TV, Italy) during the period 2006-2009.

The authors thank C. Anifantis and F. Ferrulli of the University of Bari for their cooperation in the field test.

The experimental tests, the data processing and the editorial work must be shared equivalently among the Authors.

(C) Copyright E. Schettini and G. Vo., 2013

Licensee PAGEPress, Italy

Journal of Agricultural Engineering 2013; XLIV(s2):e46

doi:10.4081/jae.2013.s2.e46

This article is distributed under the terms of the Creative Commons Attribution Noncommercial License (by-nc 3.0) which permits any noncommercial use, distribution, and reproduction in any medium, provided the original author(s) and source are credited.

\section{Introduction}

The radiometric properties of films used for crop protection influence the microclimate of the protected volume, i.e. the air temperature and relative humidity, the soil temperature, the quantity and quality of the solar radiation, modifying the growing condition of the crop in comparison with the external climatic conditions. The time stability of the radiometric properties of the film during the crop cycle cultivation is important when assessing the potential benefits of different materials on microclimate and on crop growth. The average service life for plastic films used to cover greenhouses ranges from some months up to three or four years in the Mediterranean region. Film lifetime is influenced by parameters related both to the film itself and to the environment in which the film is used (Desriac, 1991; Dilara and Briassoulis, 2000; Briassoulis, 2005; Ruiz et al., 2006; Stefani et al., 2008).

The ultra violet (UV) radiation in the solar spectrum, especially the UV-B and UV-A radiation that occur in the wavelength range from 280 $\mathrm{nm}$ to $400 \mathrm{~nm}$, is one of the factors that mainly influences the ageing degradation process by leading to bond cleavage and depolymerisation (Nijskens et al., 1990; Dilara and Briassoulis, 1998). The use of UV-stabilizers, such as UV absorbers, hindered amine light stabilizers (HALS) and nickel quenchers, mitigates the degradation through the prevention of solar radiation absorption as well as minimizing any subsequent radical oxidation reactions. UV stabilisers absorb UV radiation and dissipate it into heat; HALS additives decompose radicals while nickel quencher deactivate radicals, hampering the degradation process (Sanchez-Lopez et al., 1991).

Agrochemical substances influence greenhouse film degradation due to their active principles, method of application and frequency, greenhouse ventilation and structure (Dilara and Briassoulis, 2000). Agrochemicals based on sulphur and chlorine generate sub-products of the used pesticides that lead to a deterioration of the covering films together with a reducing of their mechanical and physical properties (Kham and Halim, 1995; Rull and Marin, 2006; Espi et al, 2007; Vox et al., 2008; Stefani et al., 2011; Schettini and Vox; 2012).

Aim of the research is to study the effects of agrochemicals containing iron, chlorine and sulphur, which are sprayed during cultivation, on greenhouse plastic films degradation. Three low density polyethylene (LDPE) greenhouse films were tested changing the UV-stabilizers added to the base polymer. Natural outdoor weathering, radiometric tests, and analyses on the absorption of selected contaminants were carried out to evaluate the detrimental effect of ageing and of agrochemical application on different covering films actually used in the Mediterranean region.

\section{Materials and methods}

Low density polyethylene (LDPE) films were manufactured on purpose by P.A.T.I. S.p.A. company (San Zenone degli Ezzelini, TV, Italy) 
with a nominal thickness of $100 \mathrm{~m}$, using the single layer blow-extrusion technology. The UV stabilizers, such as triazine UV absorbers, benzophenone UV absorbers, polymeric HALS, and N-alkoxy (NOR) HALS, were added to the basic polymers with a percentage not revealed, since these formulations are proprietary. Each film was identified by a code as shown in Table 1.

The films were exposed to natural outdoor weathering at the experimental farm of the University of Bari (Valenzano, Bari, Italy; $41^{\circ} 05^{\prime} \mathrm{N}$, $16^{\circ} 53$ ' E, $85 \mathrm{~m}$ asl). The test started in Spring 2009, allowing the highest solar irradiation of the films during the warmest period of the year, and ended when the first film was broken. Each film was used to cover two low tunnels (Figure 1): one of the tunnels was sprayed (code S) with the agrochemicals while the other one was not sprayed and used as control (code C). Each low tunnel had a length of $20.0 \mathrm{~m}$, a width of $1.0 \mathrm{~m}$ and a height of $0.8 \mathrm{~m}$, with $\mathrm{N}-\mathrm{S}$ orientation.

The agrochemicals were sprayed onto the films by a system consisting of a pump connected with pipes and nozzles located inside the low tunnels. A water solution with a foliar fertilizer containing iron

Table 1. LDPE greenhouse covering films.

\begin{tabular}{lc} 
Film code & Stabilizers \\
A4 & No stabilizers \\
D4 & NOR-HALS + triazine UV filter \\
\hline H4 & HALS + benzophenone UV filter \\
\hline
\end{tabular}

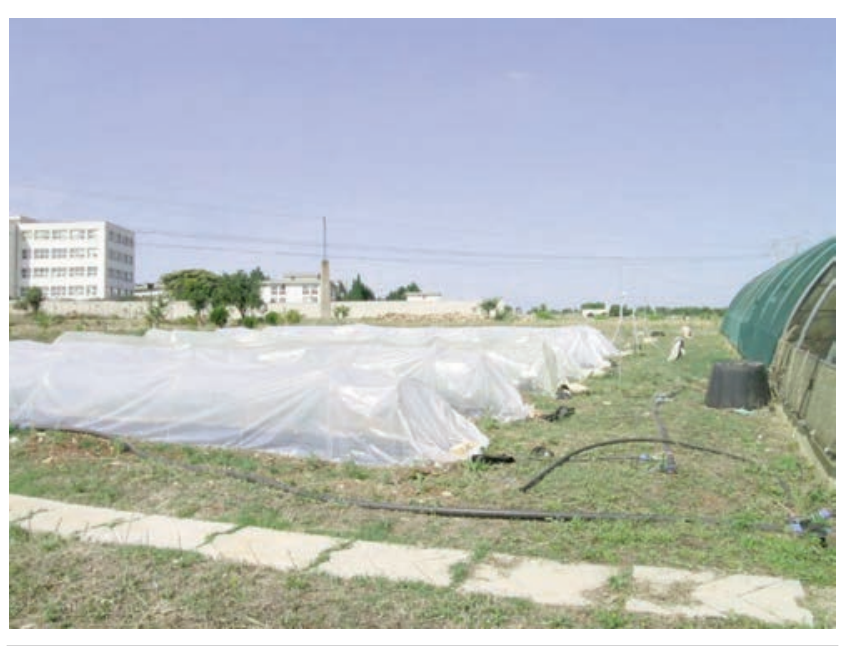

Figure 1. The experimental field at the University of Bari (Italy).
(Sequestrene® Life, Syngenta Crop Protection S.p.A., Milan, Italy), a fungicide containing sulphur (Tiovit ${ }^{\circledR}$ Jet, Syngenta Crop Protection) and a fungicide containing chlorine (Topas ${ }^{\circledR}$, Syngenta Crop Protection) was sprayed weekly during the period test. The doses of the active principles of the agrochemicals were: $0.500 \mathrm{~g} / \mathrm{m}^{2}$ for sulphur; $0.028 \mathrm{~g} / \mathrm{m}^{2}$ for chlorine; $0.034 \mathrm{~g} / \mathrm{m}^{2}$ for iron.

Solar radiation was measured by a pyranometer (model 8-48, Eppley Laboratory, Newport, RI, USA) in the wavelength range $0.3-3 \mathrm{~mm}$; data were recorded by a data logger (CR10X, Campbell, Logan, USA) every $60 \mathrm{~s}$ and stored as $15 \mathrm{~min}$ average values. The cumulative solar radiation for the exposure period was calculated.

Radiometric tests on the new films and on samples taken at the end of the trial were carried out at the University of Bari. Spectral transmissivity $T(\lambda)$ of a material is the fraction of the incident energy radiant flux that is transmitted at a specific wavelength $\lambda$. Spectral direct transmissivity in the wavelength range between 300 and $2500 \mathrm{~nm}$ were measured by means of a spectrophotometer (UV-VIS-NIR Lambda 950, Perkin-Elmer Instruments, Norwalk, CT, USA) in steps of $10 \mathrm{~nm}$ using radiation with a direct perpendicular incidence. Spectral total transmissivity was measured by means of an integrating sphere (diameter $60 \mathrm{~mm}$ ) used as receiver of the Lambda 950 spectrophotometer. Spectral diffuse transmissivity was calculated by subtracting the direct transmissivity from the total transmissivity. The transmissivity coefficients were calculated as weighted average values of the transmissivity over the wavelength interval between 300 and $2500 \mathrm{~nm}$ for the solar range, and between 400 and $700 \mathrm{~nm}$ for the photosynthetically active radiation (PAR) range using the spectral distribution of the terrestrial solar radiation as weighting function (Vox and Schettini, 2007). The transmissivity in the long wave infra-red radiation (LWIR) range between 2500 and $25000 \mathrm{~nm}$ was measured by a spectrophotometer (FT-IR 1760X, Perkin-Elmer Instruments, Norwalk, CT, USA) in steps of $4 \mathrm{~cm}^{-1}$. Spectral transmissivity was measured using radiation with a direct perpendicular incidence. The transmissivity coefficient in the LWIR range was calculated as average value of the spectral transmissivity in the wavelength range from 7500 to $12500 \mathrm{~nm}$, where the bodies at ambient temperature have the maximum energy emission as expressed by Planck's spectral distribution of emissive power (Vox and Schettini, 2007).

The absorption of chlorine, iron and sulphur was estimated at the Venezia Tecnologie laboratories (Venice, Italy), using fluorescence Xray elementary semiquantitative analysis.

\section{Results and discussion}

Table 2 show the radiometric parameters of the films tested, i.e. the total transmissivity coefficients calculated in the solar $(300-2500 \mathrm{~nm})$,

Table 2. Radiometric coefficients of the LDPE films; 0: new film; C: control film; S: sprayed film; trans.: transmissivity.

\begin{tabular}{|c|c|c|c|c|c|c|}
\hline Film & Exposure time, days & Cumulative solar radiation, $\mathrm{MJ} / \mathrm{m}^{2}$ & Total solar trans., \% & Total PAR trans., \% & Total UVA trans., $\%$ & LWIR trans., \% \\
\hline A4_0 & 0 & 0 & 89.2 & 88.6 & 80.5 & 78.8 \\
\hline A4_C & 108 & 2428 & 90.7 & 90.9 & 79.6 & 67.9 \\
\hline A4_S & 108 & 2428 & 89.8 & 89.0 & 72.4 & 55.5 \\
\hline D4_0 & 0 & 0 & 89.4 & 90.2 & 49.3 & 74.2 \\
\hline D4_C & 108 & 2428 & 90.0 & 90.3 & 50.5 & 71.9 \\
\hline D4_S & 108 & 2428 & 89.2 & 88.6 & 55.3 & 60.8 \\
\hline $\mathrm{H} 4 \_0$ & 0 & 0 & 88.1 & 88.4 & 30.2 & 72.1 \\
\hline H4_C & 108 & 2428 & 88.2 & 87.3 & 28.1 & 70.4 \\
\hline H4_S & 108 & 2428 & 87.7 & 86.6 & 31.6 & 60.4 \\
\hline
\end{tabular}


in the PAR (400-700 nm), in the UVA (320-380 nm) and in the LWIR $(7500-12500 \mathrm{~nm})$ wavelength range. These coefficients were evaluated at the beginning of each trial for the new films (coded 0 ) and at the end of the trials both for the control films (coded C), subjected only to the natural weathering, and for the sprayed films (coded S), subjected to the natural weathering and to the spray of the agrochemicals. The cumulative solar radiation was calculated from the day of the film installation. In the solar and in the PAR wavelength range the radiometric properties of all the films varied less than $5 \%$ between the values measured at the beginning of the trial and the end of the trial.

In the LWIR range the stabilised films showed variations less than $20 \%$ between the values measured at the beginning of the trial and the end of the trial; the A4 film, a not stabilised film, showed a higher decrease (about 30\% from its initial value). Figures 2 shows the spectral transmissivity of the $\mathrm{H} 4$ films in the LWIR wavelength range, between 2500 and $25000 \mathrm{~nm}$; the curves concern the new film (H4_0), the control film (H4_C) and the sprayed film (H4_S) after the exposure in the field. The $\mathrm{H} 4$ film showed changes of its radiometric properties at the end of the exposure in the field. The variation of the transmissivity in the LWIR range suggests changes in the chemical structure of the films. Greenhouse covering films must satisfy the EN 13206 (2001) standard; it establishes that the films, with a thickness of $100 \mathrm{~m}$, must have a PAR total transmissivity coefficient higher than $85 \%$. The films were always characterised by higher values for the PAR total transmissivity coefficient, ranging from $86.6 \%$ (H4_S) to $90.9 \%$ (A4_C).

Table 3 shows the absorption of the chemical contaminants, such as chlorine, iron, and sulphur, of the films tested at the end of their exposure in the field. The $\mathrm{H}$ film was characterised by the highest sulphur and chlorine absorption in comparison with the other films sprayed in the same way and at the same time intervals.

Table 3. Contaminants in the LDPE films at the end of film exposure in the field.

\begin{tabular}{lccc} 
Film & S $(p p m)$ & Cl $(\mathrm{ppm})$ & Fe $(\mathrm{ppm})$ \\
A4_S & 1600 & 250 & 150 \\
D4_S & 2100 & 170 & 150 \\
\hline H4_S & 3600 & 300 & 150 \\
\hline
\end{tabular}

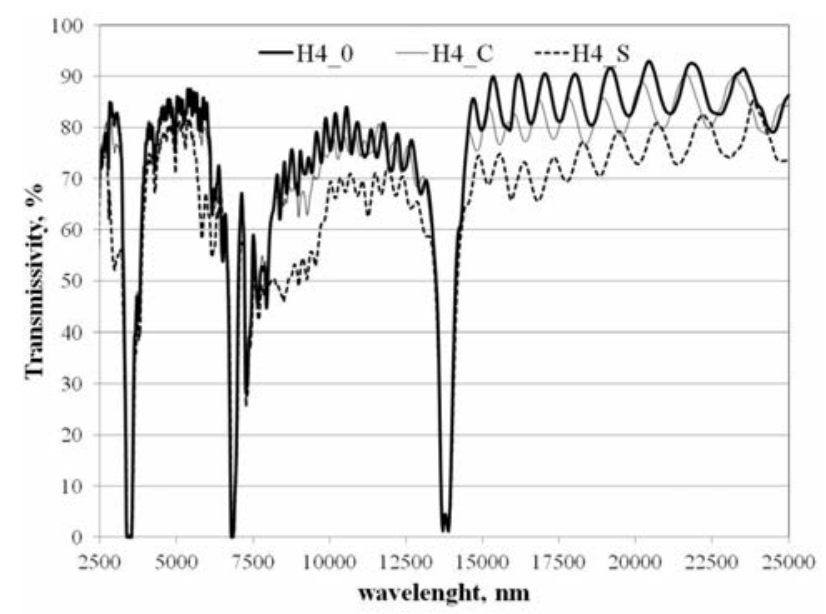

Figure 2. Long wave infrared (LWIR) spectral transmissivity of the $\mathrm{H} 4$ film in the wavelength range $2500-25000 \mathrm{~nm} ; \mathrm{H} 4$ _0, new film; H4_C: control film exposed only to natural weathering; $\mathrm{H}_{4}$ SS: film exposed to natural weathering and to agrochemicals.

\section{Conclusion}

The research showed that the radiometric properties of the films in the solar and in the PAR wavelength range were not significantly modified during their exposure to climatic agents and to the agrochemicals; the variation of the transmissivity coefficients was less than $5 \%$. Variations less of $20 \%$ of the initial value were recorded between the values measured at the beginning and the end of the test for the radiometric coefficients of the stabilised films in the LWIR wavelength range.

\section{References}

Briassoulis D. 2005. The effects of tensile stress and the agrochemical Vapam on the ageing of low density polyethylene (LDPE) agricultural films. Part I. Mechanical behaviour. Polym. Degrad. Stabil. 88: 489503.

Desriac Ph. 1991. The effect of pesticides on the life of greenhouse films. Plasticulture 89: 9-16.

Dilara P. A., Briassoulis D. 1998. Standard testing methods for mechanical properties and degradation of low density polytehylene (LDPE) films used as greenhouse covering materials: a critical evaluation. Polym. Test. 17: 549-585.

Dilara P. A., Briassoulis D. 2000. Degradation and stabilization of Lowdensity Polyethylene films used as greenhouse covering materials. J. Agric. Eng. Res. 76: 309-321.

EN 13206. 2001. Covering thermoplastic films for use in agriculture and horticulture. Comité Européen de Normalisation (C.E.N.), Brussels.

Espí E., Salmerón A., Fontecha A., García Y., Real, A. I. 2007. The effect of different variables on the accelerated and natural weathering of agricultural films. Polym. Degrad. Stabil. 92 (12): 2150-2154.

Khan J. H., Hamid S. H. 1995. Durability of HALS-stabilized polyethylene film in a greenhouse environment. Polym. Degrad. Stabil. 48: 137142.

Nijskens J., Deltour J., Albrecht E., Grataud J., Feuilloley, P. 1990. Comparative studies on the ageing of polyethylene film in the laboratory and in practical use. Plasticulture 87: 11-20.

Ruiz P., Pagani F., Vulic I., Lobo F. 2006. Is the service life of greenhouse covers determined by exposure to the sun or by contact with agrochemical substances? Plasticulture 125: 37-49.

Rull F., Marin A. 2006. The influence of metham-sodium on the degradation of films used as covers in greenhouse. Plasticulture 126: 7-19.

Sanchez-Lopez S., Prado H. L., Ramirez E., Mendoza N. 1991. Recycling of waste agricultural polyethylene film. Plasticulture 92: 49-53.

Schettini E., Vox G. 2012. Effects of Agrochemicals on the Radiometric Properties of Different anti-UV Stabilized EVA Plastic Films. Acta Horticulturae 956: 515-522.

Stefani L., Schettini E., Vox G. 2011. Correlation between agrochemicals, solar radiation and mechanical properties of greenhouse plastic films. Acta Horticulturae 893: 281-288.

Stefani L., Zanon M., Modesti M., Ugel E., Vox G., Schettini E. 2008. Reduction of the Environmental Impact of Plastic Films for Greenhouse Covering by Using Fluoropolymeric Materials Acta Horticulturae 801: 131-138.

Vox G., Schettini E. 2007. Evaluation of the radiometric properties of starch-based biodegradable films for crop protection. Polym. Test. 26 (5): 639-651

Vox G., Schettini E., Stefani L., Modesti M., Ugel E. 2008. Effects of Agrochemicals on the Mechanical Properties of Plastic Films for Greenhouse Covering. Acta Horticulturae 801: 155-162. 